\title{
Composition and amount of nutrients entering the soil with cotton biomass and green manure
}

\section{Hasanova Aynur Oruj ${ }^{1}$, Huseynov Nizami Vidadi², Gahramanova Ramila Firuddin ${ }^{3}$, Orujova Ramala Nabil $^{4}$, Huseynova Aysel Mamadbagir ${ }^{5}$}

${ }^{1}$ Doctor of Philosophy in Agricultural Sciences,Head of the Department of General Agriculture, Genetics and selection

${ }^{2}$ Doctor of Philosophy in Agricultural SciencesAssistant of the Department of General Agriculture, Genetics and selection

${ }^{3}$ Doctoral studentAssistant of the Department of General Agriculture, Genetics and selection

${ }^{4}$ Doctoral studentAssistant of the Department of General Agriculture, Genetics and selection

${ }^{5}$ Doctoral studentAssistant of the Department of General Agriculture, Genetics and selectionAzerbaijan State

Agrarian UniversityGanja, Azerbaijan

qehremanova1977@mail.ru

Article History: Received: 11 January 2021; Accepted: 27 February 2021; Published online: 5 April 2021

Abstract: The experience of developed countries in the field of agriculture and research results show that high efficiency from mineral fertilizers can be obtained on fertile soils. That is, the soil should contain a large amount of organic substances, microelements, beneficial microorganisms, various enzymes that activate microbiological processes, normalize and optimize the nutritional, thermal and water-physical properties of the soil. This can be achieved by regularly applying crop residues and organic fertilizers to the soil. Siderata - green fertilizers - are of great importance for increasing soil fertility.

Keywords: cotton, barley, winter peas, nutrients.

\section{Relevance of the topic}

Like all countries of the world, Azerbaijan also faces various environmental problems. Uncontrolled use of chemicals, degradation of fertile lands (erosion, salt marshes), a decrease in biodiversity is a deterioration in the quality of agricultural products. All these problems are associated with the long-term use of fertilizers and pesticides, which has led to the depletion and pollution of vast areas of soil due to decades of intensive production of monocultures without rotation.

In today's globalized world, there is a need for new systems of biological farming in agriculture. Long-term research work carried out in the farming system shows that when cultivating crops, especially cotton, without using mineral fertilizers, pesticides, herbicides, you can get high yields and increase soil fertility due to organic matter.

Thus, in order to obtain environmentally friendly products in agriculture from the point of view of protecting the environment and soil, the development of alternative farming systems and new cultivation technologies is one of the urgent problems.

\section{Objective.}

Given the urgency of the problem, the main goal of the study is to develop effective alternative agrotechnical methods to increase soil fertility and obtain a high-quality product from cotton without the use of fertilizer in poorly supplied gray-brown (chestnut) soils in the Ganja-Gazakh region of the Republic of Azerbaijan.

For the first time in the course of the study, the role of green manure was revealed for the production of highquality cotton raw materials from the Ganja-114 cotton varieties on irrigated gray-brown (chestnut) soils.

\section{Methodology.}

The research work was carried out on the experimental field of the Ganja Regional Agrarian-Scientific and Information-Consulting Center.

The Ganja-114 variety was used as a research material. Sowing was carried out in 6 variants, 4-fold repetition, the area of each plot was $120 \mathrm{~m}^{2}(40 \mathrm{~m} \times 3 \mathrm{~m})$, sowing was carried out by an ordinary (band) method with a seeding pattern of $60 \times 15 \mathrm{~cm} .80 \%$ of phosphorus and potassium were introduced under the arable layer, and the remaining $20 \%$ was added to top dressing, and nitrogen was introduced 2 times to top dressing. 
There were sown $100 \mathrm{~kg} / \mathrm{ha}$ of barley, $60 \mathrm{~kg} / \mathrm{ha}$ of winter peas. Of mineral fertilizers, nitrogen was introduced in the form of ammonium nitrate (34.7\%), phosphorus in the form of superphosphate $(18.7 \%)$ and potassium in the form of potassium sulfate $(46 \%) .80 \%$ of phosphorus and potassium were introduced for plowing, the remaining $20 \%$ in top dressing, and nitrogen was introduced 2 times as top dressing.

The field experiment scheme is as follows:

1. Control (every year the guzapai are removed from the site);

2. $\mathrm{N}_{90} \mathrm{P}_{120} \mathrm{~K}_{90}$ (every year the guzapai are removed from the site);

3. Every year guzapai is crushed and introduced for plowing;

4.Before the last vegetative irrigation, barley is sown in the cotton aisle, and in December the entire aboveground part, together with the guzapai, is crushed and introduced into the subsoil, and in the spring, cotton is sown;

5. Before the last vegetative irrigation, winter peas are sown in the tractor aisle, and in December the entire aboveground part, together with the guzapai, is crushed and introduced into the subsoil, and cotton is sown in the spring;

6. Before the last vegetative irrigation, a mixed sowing of winter peas with barley is carried out in the aisle of cotton, and in December the entire above-ground part, together with the guzapai, is crushed and applied for plowing. In the spring cotton is sown.

In Russia, research by B.P. Irmulatova, A.K. Sarbasov and B.A. Mustafayev found that on light loamy dark chestnut soils in a layer of $0-20 \mathrm{~cm}$ in the field, mixture sowing of sunflower and corn lets to obtain green mass 17.7-19.0 t / ha, in a wheat field for grain $10.4 \mathrm{t} / \mathrm{ha}$, masses of perennial grasses $20.7 \mathrm{t} / \mathrm{ha}$, including Sudanese grass $13.1 \mathrm{t} / \mathrm{ha}$, millet, rye and barley 12.4-12.8 $\mathrm{t} / \mathrm{ha}$, wheat and buckwheat 10.4-10.8 $\mathrm{t} / \mathrm{ha}$, and also the root mass of plants and the remains of straw [3, p.2-5].

In studies carried out in Russia, the effect of plant residues on the accumulation of organic compounds in the soil and the yield of crops grown in the crop rotation system was studied. It was found that with a decrease in the amount of humus in the control field, the amount of humus in the areas sown with perennial legumes remained at the originally studied level. Biologization significantly increased the yield of sunflower grain by $0.10-0.28 \mathrm{t} / \mathrm{ha}$ and the yield of clover as green fodder by $12.38 \mathrm{t} /$ ha $[1, \mathrm{p} .6-9]$.

Research carried out by A.V. Dedov, M.N. Esmyanova, V.A. Semikin, N.I. Kartamishev, show that annually, as a result of grain alternation in the field, up to $30 \%$ of the biomass enters the soil, and during the grain-grass alternation, the biomass entering the soil increases by $12-16 \%$ [2, p.9-11].

Research conducted by S.A. Pavlova, E.S. Pesterova and G.E. Zakharova in the Republic of Yakutia, showed that perennial grasses as a conveyor of greenery play a key role in increasing productivity and soil fertility [4, p.44-47].

Research carried out by M.Y. Rzayev and Z.M. Abdullaeva in the conditions of Absheron, showed that after harvesting, agricultural crops in the form of root mass and root residues cause a large amount of organic matter to enter the soil, which, in turn, improves soil fertility. The root mass of plants and the remains of straw under the influence of microorganisms decompose into organic matter [5, p.220-223].

The biomass, chemical composition and amount of nutrients in cotton and green manure entering the soil were studied in 2017-2018. In the first year of the study (2016), it was revealed that gray-brown (chestnut) soils are poorly enriched in exchangeable forms of nitrogen, phosphorus and potassium. Nitrogen, phosphorus and potassium in the $0-30 \mathrm{~cm}$ layer were -0.17 , respectively; $0.18 \%$ vs. $2.53 \%$. However, in the lower layers, it decreased significantly, respectively - $0.05 ; 0.07 ; 1.75 \%$. Easily assimilated nitrogen 108.5-20.3, gross phosphorus 18.5-4.5; exchangeable potassium varied between 275.5 and $105.3 \mathrm{mg} / \mathrm{kg}$.

In the first year of the experiment, the amount of nutrients entering the soil was small, and in subsequent years it increased.

It has been established that each year the aboveground weight of cotton is $65.8-77.3 \mathrm{c} / \mathrm{ha}$; total nitrogen $0.68-0.88 \%$, total phosphorus $0.38-0.62 \%$, total potassium $0.88-1.25 \%$, NPK entering the soil were respectively $44.7-68.0 ; 25.0-48.5$ and $58.0-96.6 \mathrm{~kg} / \mathrm{ha}$.

Green mass of barley 68.6-97.6 c / ha, dry matter in green mass 19.5-20.7\%, dry weight 13.4-20.7 c / ha, total amount of NPK in dry mass $0.47-0.58 \%$; $0.18-0.25 \%$ and $0.95-1.08 \%$, but NPK entering the soil, respectively, amounted to $6.3-11.3 ; 2.4-4.9$ and $12.7-21.2 \mathrm{~kg} / \mathrm{ha}$. 
Green mass of winter peas 45.2-55.3 c / ha, dry matter in green mass $19.8-21.8 \%$, dry weight $9.0-12.1 \mathrm{c} / \mathrm{ha}$, and NPK entering the soil was $10,4-14.0 ; 2.6-4.0$ and $4.0-6.4 \mathrm{~kg} / \mathrm{ha}$.

\section{Conclusions.}

We found that, in the 6th option (before the last vegetative irrigation, a mixed sowing of winter peas with barley is carried out and in December, the entire aboveground part, together with the guzapai, is crushed and applied for plowing), the nutrients entered into the soil varied: nitrogen 61.4- 87.5; phosphorus 30.0-54.3 and potassium 74.7-116.2 $\mathrm{c} /$ ha. And this shows that, before the last vegetative irrigation, where a mixed sowing of winter peas with barley is carried out, and in December, the entire aboveground part, together with the guzapai, is crushed and applied for plowing, it is possible to increase soil fertility by biological methods. Thanks to the influence of green manure, the agrochemical, water-physical properties of the soil have improved and the indicators of productivity and quality of cotton products have increased.

\section{References}

1. Dedov A.A., Nesmeyanova M.A., Dedov A.V. Influence of the rate of decomposition of plant residues on the labile organic matter of the soil and the yield of crop rotation // M .: Agrarian science, 2017, No. 4, p. 69

2. Dedov A.V., Nesmeyanova M.A., Dedov A.A. Soil organic matter and productivity of crop rotations when using various methods of biologization and soil cultivation // M .: Agrarian science, 2018, No. 4, p. 9-11

3. Irmulatov B.R., Sarbasov A.K., Mustafaev B.A. The influence of preceding and technologies in the regulation of the mode of introduction of batteries // M .: Agrarian science, 2017, No. 4, p.2-5

4. Pavlova S.A., Pestereva E.S., Zakharova G.E. The mode of using regional perennial grasses on a green conveyor in the conditions of Central Yakutia // M .: Agrarian science 2018, No. 4, p. 44-47

5. Rzayev M.Y., Abdullayeva Z.M. Agrobotanical indicators and productivity of plants in alternating and continuous crops in the conditions of irrigation of Absheron // Collection of Scientific Works of AzEETI, XXIV c. Baku: Teacher, 2013, p.220-223 